\title{
Use of Different Styles of Teaching Psychiatry and Addictology to Medical Students Considering Their Types of Memory
}

\author{
S. Savka*, R. Rudnitskiy, N. Karvatskaya, N. Grinco, S. Rotar
}

\section{Abstract}

The article reflects the peculiarities of teaching psychiatry and addictology to medical students considering their learning styles and types of memory. The peculiarities of different teaching styles for the improvement of knowledge assimilation are highlighted. The significance of psychiatry and addictology as a clinical discipline in the future activity of medical specialists is shown.

\section{Keywords}

psychiatry and addictology; students; types of memory; teaching styles

Bukovinian State Medical University, Chernivtsi, Ukraine

${ }^{\star}$ Corresponding author: Savka.Svitlana@bsmu.edu.ua

\section{Introduction}

The educational process in modern universities is organized considering information technologies and is oriented on the formation of an educated, harmoniously developed personality being capable of constantly updating his/her knowledge and professional mobility. It is also based on the principles of humanism, democracy, consistency and continuity. Moreover, recently, the educational process in medical higher education institutions in Ukraine has been organized according to the European Credit Transfer and Accumulation System (ECTS) [1].

The aforementioned system allows to upgrade the level of professional skills of Ukrainian medical students to the European standard. Moreover, the ECTS is a principal factor of improving the quality of education and establishment of international contacts $[2,3]$.

Despite the acquisition of knowledge, medical students should be able to apply it and develop clinical thinking. Therefore, the objective of the research was to investigate medical students' learning styles and the major features of information assimilation.

\section{Discussion}

Medical students study psychiatry during their 4th year of study, as to study this subject they need basic knowledge obtained during previous three years. This discipline is based on studying psychology, anatomy, physiology, pathology, pathophysiology, biological and bioorganic chemistry, propaedeutics of internal medicine, pharmacology, neurology and is integrated with these disciplines. The course consists of 135 hours (4.5 ECTS credits) of psychiatry and addictology.

Teaching process is conducted at a high scientific and practical level; modern methods of knowledge control and remote technologies are combined with classical techniques.

Lecture course includes 20 hours providing the information about the mental health system in Ukraine, general psychopathology, etiology, pathogenesis, as well as treatment, prevention and examination of mental disorders. All lectures are accompanied by a demonstration of illustrations and communication with patients.

According to the course, 70 hours of practical classes are required for the fourth-year medical students studying at educational institutions of III-IV accreditation levels. Under the direct teacher's supervision, students analyze key issues of general psychopathology, psychiatric nosology and addictology; they undergo testing and solve situational problems.

Each student has his/her own style and way of perception. There are three main categories of learning styles: visual, kinesthetic and auditory. Some students effectively study visual information provided by pictures, images, charts, slides. Auditory type includes students, who focus on auditory sensations; they attend lectures, listen to audio files. Students of kinesthetic learning style learn by acting: they draw up schemes, take part in communication with patients and roleplaying games.

During our research, we examined 210 fourth-year students. 96 students had the visual learning style, 59 students had the auditory learning style and 55 students had the kinesthetic learning style. The determination of students' learning styles leads to making the education process more effective and interesting. Moreover, it helps select the exercises as well 
as the ways of material presentation that will be the most useful, understandable and easy to learn. Despite of the fact, that some of the learning styles better correspond to a particular subject, the highest level of understanding the information by students can be achieved only by combining them.

Successful studying includes memorization, which is the first step to the acquisition of new knowledge, information coding and releasing. The information usually passes through several filters. Sensory memory is the first one. All the information received by the sense organs is firstly stored in sensory memory. Students do not consider most of their sensations, until some unusual or interesting things appear. Thus, mostly sensations are ignored and our memory does not encode them. Therefore, during the educational process, it is important to pay attention to the fact, that the reaction to imperceptible sensory stimulation weakens. If teachers use the same teaching style and approach during long time, students become accustomed and ignore the given information. At the same time, using several styles leads to the concentration and attention.

The next stage of memorization is short-term memory. This type of memory allows students to store the information for the time needed to perform a specific task. Short-term memory usually stores the information that is important for the student and is necessary for taking some actions or information being surprising and unexpected. Repetition allows students to retain the information in short-term memory. Shortterm memory has limited capacity (only about 7 items can be stored at a time). Thus, the distribution of the information in pieces can help students use their working memory effectively and choose things worth focusing on. If short-term memory is overloaded, it is more difficult for the information to transfer into long-term memory.

The most important goal of teaching is an assimilation of the information in long-term memory. All the data remembered by a person is not stored separately; it becomes a part of associations. The more associations are created, the easier it will be for a student to release the information. For example, a student who knows the formula for ethanol, its mechanism of action, its effect on the organism and the clinical picture of hepatitis, can remember the clinical picture of alcoholic delirium easier and faster. However, if a student does not have enough knowledge of basic subjects and studies only new material, it will be more difficult for him to memorize it. Therefore, the study of physiology, psychology, pharmacology, biochemistry and internal medicine is very important.

The information obtained by students has to be structured using charts, tables and multimedia presentations. If there is a lot of information and it is not structured, it is more difficult to remember it.

We recommend our students to study the subject considering its context. For example, theoretical knowledge is better received in the library, while practical skills should be achieved in a clinic. The information should be encoded similar to the environment, where it will be released from the memory. Therefore, students communicate with patients and solve situational problems during every practical class memorizing different symptoms and syndromes. An emotional context is one of the most difficult. The emotional context during practical classes differs from that during the working process, as a doctor is responsible for the patient's life. During practical classes, we use role-play technique, namely virtual patient technique, that allows students to create a certain emotional context. One student usually represents a patient with a particular disease and syndrome, while other students represent doctors and assistants, who diagnose the disease, plan its examination and treatment.

During distance learning, we often use multiple choice tests, as the identification of the correct information is easier for memory. However, to verify the reproduction of the information, we use the exercises for clinical case that are evaluated by teachers. To make the tasks more similar to real clinical situations, we offer our students exercises that train memory and practical skills such as interviewing patients and planning examination and treatment depending on the particular disease.

There are different types of memory that have different mechanisms of coding and releasing information. Declarative or semantic memory stores all the information, that can be clearly explained. Episodic memory refers to personal experience and life situations. Conditioned-reflex memory contains unconscious mechanisms involving automatic reactions. These mechanisms can be congenital or resulting from practice and repetition. Procedural memory allows us to take consistent actions that require step-by-step approach. Procedural memory may be unconscious as well. This is due to muscle memory, for example, when an action can be performed without any conscious efforts, while the concentration is focused on other things.

Summarizing the above, memory is based on coding and releasing the information; students receive a continuous flow of information, thereby paying attention to the things being important for them; students become accustomed to repetitive stimuli, therefore, the learning process cannot be monotonous; it is important to group information as working memory is limited; the information is retained in working memory when it is needed for completing some tasks only, thus, students should interview patients and solve situational problems; the information is easily memorized, when it is connected with many associations; if the emotional contexts during studying and releasing information are similar, students can effectively use it in practice; clinical case reporting facilitates information absorption.

\section{Conclusions}

1. The implementation of psychiatry curriculum in the combination with modern technologies and classic teaching methods forms the students' ability to use knowledge of psychiatry in both further education and professional life, broadens their outlook concerning the application of their professional skills, lays the founda- 
tions of a healthy lifestyle as well as the prevention of mental disorders.

2. Considering the students' learning styles and memory types makes the education process more adapted and approachable, the learning process - more effective and interesting, the information - understandable and easily remembered.

\section{References}

[1] About the higher education. Law of Ukraine of July 1, 2014 No. 1556-VII. Available from: http://zakon2.rada.gov.ua/laws/show/1556-18

[2] Zimenkovskyi BS, Hzhehotskyi MR, Varyvoda YeS. European Credit Transfer-Accumulation system in the context of the reform of English teaching of foreign students at Danylo Halytsky Lviv National Medical University. Materialy XIII Vseukraiinskoii naukovo-praktychnoii konferentsii z mizhnarodnoiu uchastiu "AKTUALNI PUTANNIA YAKOSTI MEDYCHNOII OSVITY". Medychna osvita. 2016;110-112. DOI: https://doi.org/10. $11603 / \mathrm{me} \cdot \mathrm{v0i2.6228}$

[3] Zaporozhan VM, Kresyun VK, Aryayev ML, Cherneckaya OV. Study in English as a stimulator of education quality and international contacts. Medychna osvita. 2011;2:45-47. DOI: https://doi.org/10.11603/ me.v0i2.863

[4] Julie Dirksen. Design for How People Learn. Berkeley: New Riders; c2012. 260p.

Received: 19 May 2017

Revised: 27 Sept 2017

Accepted: 28 Sept 2017 